\title{
Theoretical Conformational Analysis of Disulfide-Linked Tetrapeptides Ac-Cys-Pro-Xaa-Cys-NHMe Having Hydrophobic Xaa Amino-Acid Residues
}

\author{
Yuichirou Ishikawa, Yoshiaki Hirano, Jun Yoshimoto, ${ }^{*}$ Masahito OKa, ${ }^{* * \dagger}$ \\ and Toshio HaYASHI** \\ Department of Applied Chemistry, Osaka Institute of Technology, \\ Asahi-ku, Osaka 535, Japan \\ * Graduate School of Human Informatics, Nagoya University, \\ Chikusa-ku, Nagoya 464-01, Japan \\ ** Research Institute for Advanced Science and Technology, \\ Osaka Prefecture University, Sakai, Osaka 593, Japan
}

(Received September 18, 1997)

\begin{abstract}
Theoretical conformational analysis was carried out on four cyclic tetrapeptides Ac-Cys-Pro-XaaCys-NHMe (Xaa = Val, Phe, Leu, and norleucine) using Empirical Conformation Energy Program for Peptides (ECEPP) and optimization procedure for investigating the effects of differences in the hydrophonbic side-chain groups of Xaa residue on the $\beta$-bend conformation at the Xaa-Pro portion of cyclic peptides having the disulfide linkage. Calculated results indicate that four cyclic Ac-Cys-Pro-Xaa-Cys-NHMe essentially form type III $\beta$-bend at the Pro-Xaa portion, and also show fairly good agreement with experimental results of the NMR spectroscopy and X-ray crystallography for the tetrapeptides having Cys-Pro-Xaa-Cys sequence.

KEY WORDS $\beta$-Bend / Tetrapeptide / Disulfide Linkage / Molecular Mechanics / Empirical Conformation Energy Program for Peptides /
\end{abstract}

For creating new artificial proteins, it is very important to design them through an a priori method based on the principle relations among three attributes of proteins, i.e., amino-acid sequences, conformations, and functions. From this viewpoint, we tried theoretical conformational analysis based on the molecular mechanics calculations to find all stable local minima in the whole conformational space of peptides ${ }^{1-3}$ and polypeptides, ${ }^{4-11}$ which are model molecules having key sequences in native proteins, and also showed that the lowest-energy conformations or the ensembles of the low-energy conformations of such molecules have reasonable structural characters which explain molecular functions of native proteins. Such conformational characters theoretically proposed for the peptides and polypeptides were also preliminary supported by experimental results. ${ }^{12-15}$

Disulfide-linkages between two cystine residues are very important to introduce topological constraint into proteins, and contribute to stabilize the specific three-dimensional structure of proteins. In previous works, ${ }^{16-18}$ theoretical conformational analysis was carried out on cyclic tetrapeptides Ac-Cys-Pro-GlyCys-NHMe ${ }^{16}$, Ac-Cys-Pro-Ala-Cys-NHMe ${ }^{17}$, and Ac-Cys-Pro-D-Ala-Cys-NHMe ${ }^{18}$ using Empirical Conformation Energy Program for Peptides (ECEPP) ${ }^{19}$ for designing amino-acid sequences for the loop portions of artificial functional proteins. Calculated results indicate that the disulfide-linkage stabilizes the specific $\beta$-bend structure at the Pro-Xaa portions. That is, cyclic AcCys-Pro-Gly-Cys-NHMe and Ac-Cys-Pro-D-AlaCys-NHMe form compactly folded conformations with type II $\beta$-bend at the Pro-Gly and Pro-D-Ala portions, respectively, and cyclic Ac-Cys-Pro-Ala-Cys-NHMe also forms those with type III $\beta$-bend at the Pro-Ala

\footnotetext{
† To whom all correspondence should be addressed.
}

portion. It means that the bend type at the -CysPro-Xaa-Cys- sequence could be controlled by selecting the amino-acid residue Xaa (Xaa = Gly, Ala, and D-Ala). In this work, as a further step for investigating the effects of the difference in the side-chain groups on the conformational preference of the cyclic peptides with disulfide linkage, theoretical conformational analysis was carried out on four cyclic tetrapeptides Ac-CysPro-Xaa-Cys-NHMe (Xaa = Val, Phe, Leu, and norleucine abbreviated as Nle) using ECEPP ${ }^{19}$ and optimization procedure. ${ }^{20}$

\section{THEORETICAL}

All conformational energy calculations were carried out on four disulfide-linked oligopeptides Ac-Cys-ProXaa-Cys-NHMe (Xaa =Val, Phe, Leu, and Nle) with the energy functions of ECEPP. ${ }^{19}$ During minimizations using the Powell argorism, ${ }^{20}$ all $\psi$ of Pro, $\left(\phi, \psi, \chi^{1}, \chi^{2,1}, \chi^{2,2}\right)$ of Val, $\left(\phi, \psi, \chi^{1}, \chi^{2}\right)$ of Phe, $(\phi, \psi$, $\left.\chi^{1}, \chi^{2}, \chi^{3,1}, \chi^{3,2}\right)$ of Leu, $\left(\phi, \psi, \chi^{1}, \chi^{2}, \chi^{3}, \chi^{4}\right)$ of Nle, and $\left(\phi, \psi, \chi^{1}\right)$ of cystine were allowed to vary. $\phi$ of Pro was fixed at $-75^{\circ}$. All other backbone dihedral angles were fixed at $180^{\circ}$. All combinations of single residue minima of Cys, Pro, and Xaa residues were used as starting conformations of minimization. Selected numbers of all stable single-residue minima were $21,4,10$, 28, 15, and 60 for Cys, Pro, Val, Phe, Leu, and Nle, respectively.

A bend (occurring at $i+1$ and $i+2$ th residues) is defined as a conformation in which $R \leqq 7 \AA$ ( $R$ is the distance between $i$ th $\mathrm{C}^{\alpha}$ and $i+3$ th $\mathrm{C}^{\alpha}$ atoms) and is classified into one of the eleven types given in Table I of ref 21 . A polar hydrogen atom and an oxygen or nitrogen atom with an interatomic distance of less than $2.3 \AA$ are regarded to be hydrogen-bonded. The conformational 
Table I. Minimum Energy Conformations ${ }^{\mathrm{a}}$ of Ac-Cys-Pro-Val-Cys-NHMe

\begin{tabular}{|c|c|c|c|c|c|c|c|c|c|c|c|}
\hline \multirow{2}{*}{$\begin{array}{l}\text { Conformational } \\
\text { letter code }\end{array}$} & \multirow{2}{*}{$\frac{\Delta E^{\mathrm{b}}}{\mathrm{kcal} \mathrm{mol}}$} & \multirow{2}{*}{$v^{\mathrm{c}}$} & \multirow{2}{*}{\multicolumn{2}{|c|}{$\begin{array}{l}\text { Bend } \\
\text { type }^{\text {d }}\end{array}$}} & \multirow{2}{*}{$\phi_{\text {Cys } 1}$} & \multirow{2}{*}{$\psi_{\mathrm{Cys} 1}$} & \multirow{2}{*}{$\psi_{\text {Pro }}$} & \multirow{2}{*}{$\phi_{\text {val }}$} & \multirow{2}{*}{$\psi_{\mathrm{val}}$} & \multirow{2}{*}{$\phi_{\text {Cys } 4}$} & \multirow{2}{*}{$\psi_{\text {Cys } 4}$} \\
\hline & & & & & & & & & & & \\
\hline DAAA & 0.00 & 0.599 & III & III & -152 & 89 & -18 & -80 & -24 & -72 & -47 \\
\hline DAAC & 0.88 & 0.137 & III & I & -152 & 89 & -15 & -84 & -19 & -79 & 84 \\
\hline EACE & 1.08 & 0.097 & I & - & -160 & 150 & -64 & -101 & 99 & -166 & 155 \\
\hline DFA*E & 1.77 & 0.031 & II & - & -152 & 88 & 130 & 56 & 71 & -132 & 144 \\
\hline EACD & 1.79 & 0.030 & I & - & -159 & 150 & -64 & -101 & 100 & -166 & 56 \\
\hline $\mathrm{DFA}^{*} \mathrm{D}$ & 1.93 & 0.024 & II & - & -152 & 87 & 131 & 56 & 69 & -130 & 84 \\
\hline A*AAA & 2.12 & 0.017 & III & III & 60 & 86 & -17 & -82 & -25 & -69 & -48 \\
\hline DAAA & 2.20 & 0.015 & III & III & -152 & 86 & -22 & -77 & -23 & -69 & -48 \\
\hline $\mathrm{ECA}^{*} \mathrm{E}$ & 2.29 & 0.013 & II & - & -157 & 151 & 76 & 59 & 90 & -143 & 156 \\
\hline$E C A * E$ & 2.50 & 0.009 & II & - & -159 & 154 & 114 & 57 & 83 & -153 & 154 \\
\hline
\end{tabular}

${ }^{a}$ All minima with $\Delta E<2.73 \mathrm{kcal} \mathrm{mol}^{-1} .{ }^{\mathrm{b}} E_{0}=-3.65 \mathrm{kcal} \mathrm{mol}^{-1}, \Delta E=E-E_{0} . \quad{ }^{\mathrm{c}}$ Normalized Boltzmann factor at $300 \mathrm{~K}$. Bend type for Pro-Val and Val-Cys.

energy per whole molecule, $\Delta E$ is defined by $\Delta E=E-E_{0}$, $E_{0}$ is the value of $E$ at the global minima on the potential energy surface of the particular molecules. Vicinal $\mathrm{NH}-\mathrm{C}^{\alpha} \mathrm{H}$ coupling constants ${ }^{3} J_{\mathrm{NH}-\mathrm{C}^{\alpha} \mathrm{H}}$ of Cys and Xaa residues for Ac-Cys-Pro-Xaa-Cys-NHMe were computed using the equation derived by Bystrov et al. ${ }^{22}$ and normalized Boltzmann factor $(v)$ for all minima with $\Delta E<3 \mathrm{kcal} \mathrm{mol}^{-1}$. Conformational space is divided into 16 regions with conformational letter codes shown in Figure 2 of ref 23 . All molecular diagrams are described by the modified PEPCON program which is a new version of the original PEPCON ${ }^{24}$ and NAMOD $^{25}$ programs.

\section{RESULTS AND DISCUSSION}

Stable Conformations of Ac-Cys-Pro-Val-Cys-NHMe

There were 425 energy minima for Ac-Cys-ProVal-Cys-NHMe with $\Delta E<10.0 \mathrm{kcal} \mathrm{mol}^{-1}$, and 10 of them $\left(\Delta E<2.73 \mathrm{kcal} \mathrm{mol}^{-1}\right)$ are shown in Table I. The lowest-energy conformation is a DAAA conformation (D, A, A and A are conformational letter codes for the Cys1, Pro, Val, and Cys4 residues, respectively.) taking type III-III double-bend at the Pro-Val-Cys portion as shown in Figure 1. This conformation shows excellently good agreement with the results of X-ray crystallography for the cyclic Ac-Cys-Pro-Val-Cys-NHMe by Falcomer et al. ${ }^{26}$ That is, $\left(\phi_{\mathrm{Cys} 1}, \psi_{\mathrm{Cys} 1}, \phi_{\mathrm{Pro}}, \psi_{\mathrm{Pro}}, \phi_{\mathrm{Val}}, \psi_{\mathrm{Val}}, \phi_{\mathrm{Cys} 4}\right.$, $\left.\psi_{\text {Cys } 4}, \chi_{\text {Cys } 1}^{1}, \chi_{\text {Cys } 1}^{2}, \chi_{\text {Cys } 4}^{1}, \chi_{\text {Cys } 4}^{2}, \chi_{\mathrm{ss}}\right)=(-152,89,-75$, $-18,-80,-24,-72,-47,-172,-139,-64,77,71)$ and $(-135,73,-60,-29,-72,-18,-73,-16,-170$, $-142,-66,74,78)$ for theoretically and experimentally evaluated values, respectively. An experimental value of $\chi_{\text {Val }}^{1}$ is not shown in Table $\mathrm{V}$ of ref 26 . However, a stereo diagram of the crystal structure of the cyclic Ac-CysPro-Val-Cys-NHMe shown in Figure 6 of ref 26 indicates that the rotational state of the $\mathrm{C}^{\alpha}-\mathrm{C}^{\beta}$ bond of the Val residue is trans conformation. This is also consistent with the theoretically evaluated $\chi_{\mathrm{Val}}^{1}=175$. Moreover, this conformation is stabilized by a hydrogen-bond, (Val) $\mathrm{N} \cdot \mathrm{HN}(\mathrm{Cys} 4)$ and a favorable hydrogen-bond-like interaction (Cys1) $\mathrm{CO} \cdots \mathrm{HN}(\mathrm{Cys} 4)$. It means that amido proton of the Cys4 residue is shielded from the solvent. This structural character is also supported by the small temperature dependence of the chemical shift of the Cys4 amido proton $\left(1.9 \mathrm{ppb} \mathrm{K}^{-1}\right)$ in
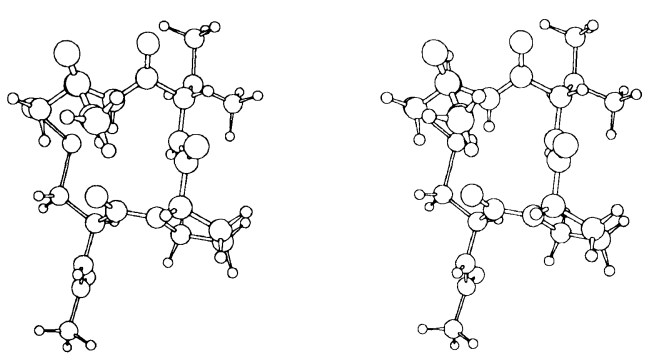

Figure 1. Lowest-energy conformation (DAAA) of Ac-Cys-ProVal-Cys-NHMe.

$\left(\mathrm{CD}_{3}\right)_{2} \mathrm{SO}^{27}$ The 2nd low-energy conformation $(\Delta E=$ $0.88 \mathrm{kcal} \mathrm{mol}^{-1}$ ) is a DAAC one taking type III-I double bend at the Pro-Val-Cys portion. This conformation almost corresponds to the lowest-energy one except for the value of $\psi_{\mathrm{Cys} 4}$, i.e., the conformational difference between them is only in the direction of the peptide group at the $\mathrm{C}$-terminal. The DAAA and DAAC conformations are only two stable ones with $\Delta E<1 \mathrm{kcal} \mathrm{mol}^{-1}$. Moreover, all 15 minima with $\Delta E<3 \mathrm{kcal} \mathrm{mol}^{-1}$ take $\beta$-bends at the Pro-Val portion. Most are types III and I with theoretically estimated occurring probability of 0.77 and 0.15 , respectively. Some takes the type II $\beta$-bend at the Pro-Val portion with theoretically estimated occurring probability of 0.08 . As the type I $\beta$-bend is similar to the type III $\beta$-bend, the type III( or I) $\beta$ bend structure is essentially a favorable conformation for the Pro-Val portion of Ac-Cys-Pro-Val-CysNHMe. These overall conformational features present good agreement with those estimated by experimental work. ${ }^{27}$

Stable Conformations of Ac-Cys-Pro-Phe-Cys-NHMe

There were 453 energy minima for Ac-Cys-Pro-PheCys-NHMe with $\Delta E<10.0 \mathrm{kcal} \mathrm{mol}^{-1}$, and 10 of them $\left(\Delta E<2.81 \mathrm{kcal} \mathrm{mol}^{-1}\right)$ are shown in Table II. The lowest-energy conformation is a DAAA conformation taking type III-III double-bend at the Pro-Phe-Cys portion as shown in Figure 2. This conformation is stabilized by a hydrogen-bond, (Phe) N $\cdots$ HN(Cys4) and a favorable hydrogen-bond-like interaction (Cys1)$\mathrm{CO} \cdots \mathrm{HN}(\mathrm{Cys} 4)$. It means that amido proton of the Cys4 residue is shielded from the solvent. This structural character is also supported by the small solvent shift 
Table II. Minimum Energy Conformations ${ }^{a}$ of Ac-Cys-Pro-Phe-Cys-NHMe

\begin{tabular}{|c|c|c|c|c|c|c|c|c|c|c|c|}
\hline $\begin{array}{l}\text { Conformational } \\
\text { letter code }\end{array}$ & $\frac{\Delta E^{\mathrm{b}}}{\mathrm{kcal} \mathrm{mol}^{-1}}$ & $v^{\mathrm{c}}$ & \multicolumn{2}{|c|}{$\begin{array}{l}\text { Bend } \\
\text { type }\end{array}$} & $\phi_{\mathrm{Cys} 1}$ & $\psi_{\text {Cys } 1}$ & $\psi_{\text {Pro }}$ & $\phi_{\mathrm{Phe}}$ & $\psi_{\mathrm{Phe}}$ & $\phi_{\text {Cys } 4}$ & $\psi_{\text {Cys4 }}$ \\
\hline DAAA & 0.00 & 0.430 & III & III & -152 & 90 & -16 & -85 & -15 & -78 & -47 \\
\hline $\mathrm{DABC}$ & 0.21 & 0.303 & III & - & -152 & 89 & -13 & -90 & -9 & -84 & 81 \\
\hline DAAC & 0.90 & 0.095 & III & - & -152 & 89 & -14 & -88 & -12 & -80 & 120 \\
\hline DAAA & 1.00 & 0.081 & III & III & -152 & 90 & -20 & -81 & -18 & -74 & -47 \\
\hline A*AAA & 2.27 & 0.010 & III & III & 59 & 87 & -14 & -87 & -16 & -75 & -48 \\
\hline EADE & 2.41 & 0.008 & VII & - & -156 & 151 & -47 & -149 & 93 & -155 & 157 \\
\hline DADC & 2.56 & 0.006 & VII & - & -150 & 88 & -43 & -145 & 61 & -86 & 83 \\
\hline DADD & 2.58 & 0.006 & I & - & -152 & 95 & -12 & -111 & 43 & -125 & 86 \\
\hline EADE & 2.59 & 0.006 & VII & - & -157 & 151 & -38 & -159 & 96 & -156 & 157 \\
\hline
\end{tabular}

${ }^{\mathrm{a}}$ All minima with $\Delta E<2.81 \mathrm{kcal} \mathrm{mol}^{-1} .{ }^{\mathrm{b}} \mathrm{E}_{0}=-9.32 \mathrm{kcal} \mathrm{mol}^{-1}, \Delta E=E-E_{0} . \quad{ }^{\mathrm{c}}$ Normalized Boltzmann factor at $300 \mathrm{~K}$. ${ }^{\mathrm{d}}$ Bend type for Pro-Phe and Phe-Cys.
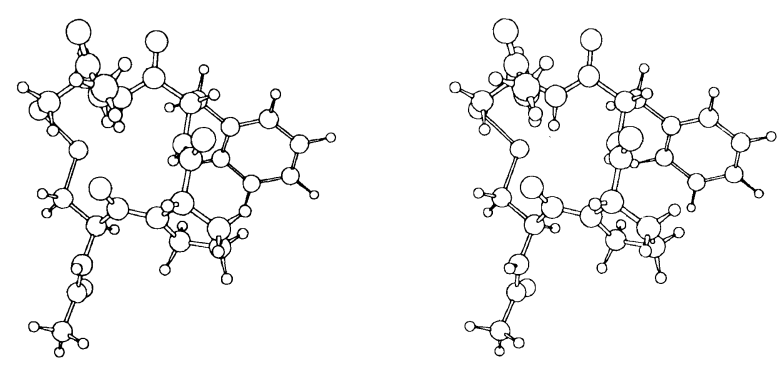

Figure 2. Lowest-energy conformation (DAAA) of Ac-Cys-ProPhe-Cys-NHMe.

value $\Delta \delta$ of Cys $4 \mathrm{NH}$ between $\left(\mathrm{CD}_{3}\right)_{2} \mathrm{SO}$ and $\mathrm{CDCl}_{3}$ for Boc-Cys-Pro-Phe-Cys-NHMe. ${ }^{28}$ Moreover, an amido proton of the Phe residue is situated in the neighborhood of amido proton of the Cys4 residue as shown in Figure 2. This is also supported by the experimental results that irradiation of the Phe NH proton results in a large $\mathrm{NOE}$ on the Cys $4 \mathrm{NH}$ proton $(72 \%)$ for Boc-Cys-Pro-Phe-Cys-NHMe in $\mathrm{CDCl}_{3} .{ }^{28}$ The 4th low-energy conformation $\left(\Delta E=1.00 \mathrm{kcal} \mathrm{mol}^{-1}\right)$ is also DAAA one which almost corresponds to the lowest-energy one with only one exception, $\chi_{\text {Phe }}^{1}$-value, i.e., $\chi_{\text {Phe }}^{1}=-55$ and -179 for the lowest- and 4th low-energy ones, respectively. The 2nd $(\Delta E=0.21$ $\left.\mathrm{kcal} \mathrm{mol}^{-1}\right)$ and $3 \mathrm{rd}\left(\Delta E=0.90 \mathrm{kcal} \mathrm{mol}^{-1}\right)$ low-energy conformations are DABC and DAAC ones, respectively, and take type III $\beta$-bend at the Pro-Phe portion. In spite of the differences in the conformational letter codes of the above four minima, they have similar backbone conformations except for the direction of the peptide group at the C-terminal. Moreover, all 15 minima with $\Delta E<3 \mathrm{kcal} \mathrm{mol}^{-1}$ take $\beta$-bends at the Pro-Phe portion. All are types III, I, and VII with theoretically estimated occurring probability of $0.96,0.02$, and 0.02 , respectively. That is, the type III $\beta$-bend structure is a dominantly favorable conformation for the Pro-Phe portion of Ac-Cys-Pro-Phe-Cys-NHMe. These overall conformational features are supported by experimental results that a substantial NOE is not observed between Phe NH and Pro $\mathrm{C}^{\alpha} \mathrm{H}^{28}$.

Stable Conformations of Ac-Cys-Pro-Leu-Cys-NHMe

There were 1157 energy minima for Ac-Cys-Pro-
Leu-Cys-NHMe with $\Delta E<10.0 \mathrm{kcal} \mathrm{mol}^{-1}$, and 10 of them $\left(\Delta E<1.35 \mathrm{kcal} \mathrm{mol}^{-1}\right)$ are shown in Table III. The lowest-energy conformation is a DAAA conformation taking type III-III double-bend at the Pro-LeuCys portion as shown in Figure 3. The backbone conformation shows excellently good agreement with the results of X-ray crystallography for the cyclic Boc-CysPro-Leu-Cys-NHMe in ref 29. Moreover, calculated side-chain conformations of $\mathrm{Cys} 1$ and $\mathrm{Cys} 4$ residues correspond to those obtained from X-ray crystallographic data in Table II of ref 29 . That is, $\left(\chi_{\text {Cys } 1}^{1}, \chi_{\text {Cys } 1}^{2}\right.$, $\left.\chi_{\text {Cys } 4}^{1}, \chi_{\text {Cys } 4}^{2}, \chi_{\text {ss }}\right)=(-173,-138,-64,77,71)$ and $(-172$, $-142,-70,74,79)$ for theoretically and experimentally evaluated values, respectively. This conformation is stabilized by a hydrogen-bond, (Leu) $\mathrm{N} \cdot \mathrm{HN}(\mathrm{Cys} 4)$ and a favorable hydrogen-bond-like interaction (Cys1)$\mathrm{CO} \cdots \mathrm{HN}(\mathrm{Cys} 4)$. It means that amido proton of the Cys 4 residue is shielded from the solvent. This structural character is also supported by the small temperature dependence of the chemical shift of the Cys4 amido proton $\left(1.2 \mathrm{ppbK}{ }^{-1}\right)$ in $\left(\mathrm{CD}_{3}\right)_{2} \mathrm{SO} .{ }^{30}$ The 2 nd lowenergy conformation $\left(\Delta E=0.01 \mathrm{kcal} \mathrm{mol}^{-1}\right)$ is also a DAAA one whose conformational character almost corresponds to the lowest-energy one except for $\chi_{\text {Leu }}^{1}=-55$ and $\chi_{\text {Leu }}^{2}=174$. The 3 rd and 5th low-energy conformations $\left(\Delta E=0.52\right.$ and $0.98 \mathrm{kcal} \mathrm{mol}^{-1}$, respectively) are DAAC ones taking type III-I double bend at the Pro-Leu-Cys portion. The backbone conformations almost correspond to the DAAA one except for the value of $\psi_{\text {Cys } 4}$. These results indicate that DAAA and DAAC conformations are energetically favorable ones for Ac-Cys-Pro-Leu-Cys-NHMe. Moreover, all 52 minima with $\Delta E<3 \mathrm{kcal} \mathrm{mol}^{-1}$ take $\beta$-bends at the Pro-Leu portion. Most are types III, I, and VII with theoretically estimated occurring probability of $0.62,0.08$, and 0.12 , respectively. Some takes type II $\beta$-bend at the Pro-Val portion with theoretically estimated occurring probability of 0.18 . As the type I and VII $\beta$-bends are similar to the type III $\beta$-bend, the type III ( or I, VII) $\beta$-bend structure is an essentially favorable conformation for the Pro-Leu portion of Ac-Cys-Pro-Leu-Cys-NHMe. These conformational features present good agreement with experimental results, i.e., non-observation of an NOE between Pro $\mathrm{C}^{\alpha} \mathrm{H}$ and Leu NH group of BocCys-Pro-Leu-Cys-NHMe in $\mathrm{CDCl}_{3}$. ${ }^{30}$ 
Table III. Minimum Energy Conformations ${ }^{\mathrm{a}}$ of Ac-Cys-Pro-Leu-Cys-NHMe

\begin{tabular}{|c|c|c|c|c|c|c|c|c|c|c|c|}
\hline $\begin{array}{l}\text { Conformational } \\
\text { letter code }\end{array}$ & $\frac{\Delta E^{\mathrm{b}}}{\mathrm{kcal} \mathrm{mol}^{-1}}$ & $v^{\mathrm{c}}$ & \multicolumn{2}{|c|}{$\begin{array}{l}\text { Bend } \\
\text { type }^{d}\end{array}$} & $\phi_{\text {Cys } 1}$ & $\psi_{\text {Cys } 1}$ & $\psi_{\text {Pro }}$ & $\phi_{\text {Leu }}$ & $\psi_{\text {Leu }}$ & $\phi_{\text {Cys } 4}$ & $\psi_{\text {Cys } 4}$ \\
\hline DAAA & 0.07 & 0.209 & III & III & -152 & 89 & -17 & -82 & -20 & -76 & -47 \\
\hline DAAC & 0.52 & 0.088 & III & I & -152 & 89 & -13 & -86 & -14 & -82 & 81 \\
\hline EADE & 0.69 & 0.067 & VII & - & -156 & 152 & -43 & -156 & 98 & -155 & 157 \\
\hline DAAC & 0.90 & 0.047 & III & I & -152 & 90 & -17 & -82 & -18 & -79 & 83 \\
\hline $\mathrm{DFA}^{*} \mathrm{E}$ & 0.91 & 0.046 & II & - & -152 & 87 & 137 & 58 & 58 & -127 & 143 \\
\hline $\mathrm{DFA}^{*} \mathrm{D}$ & 0.99 & 0.040 & II & - & -152 & 85 & 138 & 57 & 56 & -125 & 85 \\
\hline DAAA & 1.14 & 0.031 & III & III & -152 & 89 & -17 & -81 & -21 & -76 & -47 \\
\hline FADE & 1.22 & 0.027 & VII & - & -78 & 151 & -44 & -155 & 99 & -155 & 157 \\
\hline $\mathrm{DFA}^{*} \mathrm{E}$ & 1.25 & 0.026 & II & - & -152 & 87 & 134 & 57 & 63 & -130 & 144 \\
\hline
\end{tabular}

${ }^{\mathrm{a}}$ All minima with $\Delta E<1.35 \mathrm{kcal} \mathrm{mol}^{-1} .{ }^{\mathrm{b}} E_{0}=-5.39 \mathrm{kcal} \mathrm{mol}^{-1}, \Delta E=E-E_{0} . \quad{ }^{\mathrm{c}}$ Normalized Boltzmann factor at $300 \mathrm{~K}$. ${ }^{\mathrm{d}}$ Bend type for Pro-Leu and Leu-Cys.

Table IV. Minimum Energy Conformations ${ }^{\mathrm{a}}$ of Ac-Cys-Pro-Nle-Cys-NHMe

\begin{tabular}{|c|c|c|c|c|c|c|c|c|c|c|c|}
\hline $\begin{array}{l}\text { Conformational } \\
\text { letter code }\end{array}$ & $\frac{\Delta E^{\mathrm{b}}}{\mathrm{kcal} \mathrm{mol}^{-1}}$ & $v^{\mathrm{c}}$ & \multicolumn{2}{|c|}{$\begin{array}{l}\text { Bend } \\
\text { type }^{\text {d }}\end{array}$} & $\phi_{\text {Cys } 1}$ & $\psi_{\mathrm{Cys} 1}$ & $\psi_{\text {Pro }}$ & $\phi_{\mathrm{Nle}}$ & $\psi_{\mathrm{Nle}}$ & $\phi_{\text {Cys } 4}$ & $\psi_{\text {Cys } 4}$ \\
\hline DAAA & 0.00 & 0.237 & III & III & -152 & 89 & -18 & -81 & -21 & -76 & -47 \\
\hline DAAA & 0.29 & 0.146 & III & III & -152 & 90 & -21 & -77 & -25 & -72 & -47 \\
\hline DAAC & 0.57 & 0.091 & III & I & -152 & 89 & -14 & -85 & -15 & -82 & 81 \\
\hline DFA*E & 0.97 & 0.047 & II & - & -152 & 87 & 137 & 57 & 59 & -127 & 143 \\
\hline DFA*D & 1.05 & 0.041 & II & - & -152 & 86 & 138 & 56 & 57 & -125 & 85 \\
\hline EADE & 1.09 & 0.038 & VII & - & -156 & 152 & -44 & -155 & 98 & -154 & 157 \\
\hline $\mathrm{DFA}^{*} \mathrm{E}$ & 1.10 & 0.037 & II & - & -152 & 87 & 133 & 59 & 64 & -130 & 144 \\
\hline DAAC & 1.21 & 0.031 & III & I & -152 & 90 & -17 & -82 & -18 & -79 & 84 \\
\hline DFA*D & 1.23 & 0.030 & II & - & -152 & 86 & 134 & 58 & 62 & -128 & 84 \\
\hline DAAA & 1.41 & 0.022 & III & III & -152 & 89 & -18 & -81 & -21 & -76 & -47 \\
\hline
\end{tabular}

${ }^{\mathrm{a}}$ All minima with $\Delta E<1.60 \mathrm{kcal} \mathrm{mol}^{-1} .{ }^{\mathrm{b}} E_{0}=-5.91 \mathrm{kcal} \mathrm{mol}^{-1}, \Delta E=-E-E_{0} .{ }^{\mathrm{c}}$ Normalized Boltzmann factor at $300 \mathrm{~K}$. ${ }^{\mathrm{d}}$ Bend type for Pro-Nle and Nle-Cys.
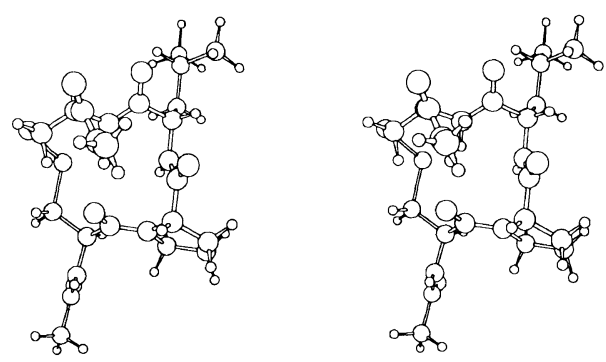

Figure 3. Lowest-energy conformation (DAAA) of Ac-Cys-Pro Leu-Cys-NHMe.

Stable Conformations of Ac-Cys-Pro-Nle-Cys-NHMe

There were 2295 energy minima for Ac-CysPro-Nle-Cys-NHMe with $\Delta E<10.0 \mathrm{kcal} \mathrm{mol}^{-1}$, and 10 of them $\left(\Delta E<1.60 \mathrm{kcal} \mathrm{mol}^{-1}\right)$ are shown in Table IV. The lowest-energy conformation is a DAAA conformation taking type III-III double-bend at the ProNle-Cys portion as shown in Figure 4. This conformation is stabilized by a hydrogen-bond, (Nle) $\mathrm{N} \cdot \mathrm{HN}(\mathrm{Cys} 4)$ and a favorable hydrogen-bond-like interaction (Cys1)$\mathrm{CO} \cdot \cdot \mathrm{HN}(\mathrm{Cys} 4)$. The 2nd low-energy conformation $\left(\Delta E=0.29 \mathrm{kcal} \mathrm{mol}^{-1}\right)$ is also a DAAA one which almost corresponds to the lowest-energy one except for the value of $\chi_{\mathrm{Nle}}^{1}$. The 3 rd low-energy conformation $\left(\Delta E=0.57 \mathrm{kcal} \mathrm{mol}^{-1}\right)$ is a DAAC one taking type III-I double bend at the Pro-Nle-Cys portion. The backbone
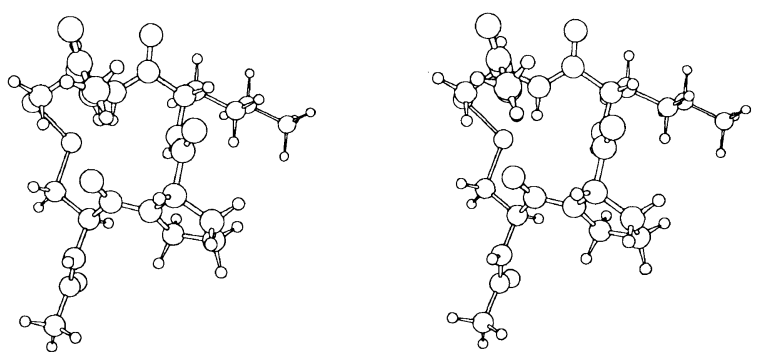

Figure 4. Lowest-energy conformation (DAAA) of Ac-Cys-ProNle-Cys-NHMe.

conformation almost corresponds to that of the lowest-energy one except for the value of $\psi_{\text {cys } 4}$, i.e., conformational differences between them are only the direction of the peptide group at C-terminal. Moreover, all 67 minima with $\Delta E<3 \mathrm{kcal} \mathrm{mol}^{-1}$ take $\beta$-bends at the Pro-Nle portion. Most are types III, I, and VII with theoretically estimated occurring probability of 0.62 , 0.09 , and 0.06 , respectively. Some takes type II $\beta$-bend at the Pro-Nle portion with theoretically estimated occurring probability of 0.23 . Calculated results indicate that the type III $\beta$-bend structure is essentially a favorable conformation for the Pro-Nle portion of Ac-CysPro-Nle-Cys-NHMe. 
Table V. Vicinal Coupling Constants $\left({ }^{3} J_{\mathrm{NH}-\mathrm{C}_{\mathrm{H}}}\right)$ of Ac-Cys-Pro-Xaa-Cys-NHMe

\begin{tabular}{lccl}
\hline & \multicolumn{3}{c}{} \\
& ${ }^{3} J_{\mathrm{NH}-\mathbf{C}^{\alpha} \mathbf{H}}$ & \multicolumn{1}{c}{ Cys4 } \\
\cline { 2 - 4 } & Cys1 & Xaa & $6.0(7.3)$ \\
Val & $7.9(7.7)^{\mathrm{a}}$ & $7.5(9.2)$ & $6.7(-)$ \\
Phe & $8.1(8.8)$ & $7.9(8.1)$ & $7.1(8.0)$ \\
Leu & $7.9(8.5)$ & $7.6(9.5)$ & $7.2(-)$ \\
Nle & $8.0(-)$ & $7.6(-)$ & $7.3(5.5)$ \\
Ala & & &
\end{tabular}

${ }^{a}$ Values in parentheses are experimental results for Boc-Cys-ProXaa-Cys-NHMe in $\left(\mathrm{CD}_{3}\right)_{2} \mathrm{SO}$ from ref 27,28 , and $31 .{ }^{\text {b }}$ From ref 17 .

Table VI. Bend Probability of Pro-Xaa portion of Ac-Cys-Pro-Xaa-Cys-NHMe

\begin{tabular}{lcccc}
\hline & \multicolumn{5}{c}{ Bend type } \\
Xaa & I & II & III & VII \\
\cline { 2 - 5 } & 0.15 & 0.08 & 0.77 & - \\
Val & 0.02 & - & 0.96 & 0.02 \\
Phe & 0.08 & 0.18 & 0.62 & 0.12 \\
Leu & 0.09 & 0.23 & 0.62 & 0.06 \\
Nle & 0.08 & 0.16 & 0.57 & 0.20 \\
Ala $^{\text {a }}$ & & & &
\end{tabular}

${ }^{\mathrm{a}}$ From ref 17

Averaged Conformational Properties of Ac-Cys-Pro$\mathrm{Xaa}-\mathrm{Cy}$ - $\mathrm{NHMe}$

Calculated vicinal $\mathrm{NH}-\mathrm{C}^{\alpha} \mathrm{H}$ coupling constants ${ }^{3} J_{\mathrm{NH}-\mathrm{C}^{\alpha} \mathrm{H}}$ of $\mathrm{Cys}$ and $\mathrm{Xaa}$ residues of Ac-CysPro-Xaa-Cys-NHMe $\left(\mathrm{X}_{\mathrm{aa}}=\mathrm{Val}\right.$, Phe, Leu, Nle, and Ala) are summarized in Table $\mathrm{V}$. These statistically averaged values showed fairly good agreement with the experimentally evaluated ones for Boc-Cys-Pro-XaaCys-NHMe in $\left(\mathrm{CD}_{3}\right)_{2} \mathrm{SO}$ solution ${ }^{27,28,31}$ within the range of ambiguousness in the relationship between $\phi$ and ${ }^{3} J_{\mathrm{NH}-\mathrm{C}_{\mathrm{H}} \mathrm{H}}$. Moreover, in our previous works on a model tetrapeptide of the repetitive portion in elastin, Ac-Val-Pro-Gly-Gly-NHMe ${ }^{1}$, and its analogue tetrapeptide, Ac-Ala-Pro-Gly-Gly-NHMe, ${ }^{32}$ it was also shown that theoretically evaluated ${ }^{3} J_{\mathrm{NH}-\mathrm{C}^{\alpha} \mathrm{H}}$ of Val, Gly, and Ala residues of them indicate good agreement with the experimental values for Boc-Val-Pro-Gly-Gly$\mathrm{OMe}$ in $\mathrm{CDCl}_{3}$ with $20 \% \mathrm{C}_{6} \mathrm{D}_{6}{ }^{33}$ and $\mathrm{HCO}-\mathrm{Ala}-$ Pro-Gly-Gly-OMe in $\mathrm{CDCl}_{3}{ }^{34}$ These results indicate the possibility that ensemble of stable conformations obtained theoretically can express actual ensemble of conformations in solution for the oligopeptides having strong structural constraint such as the disulfide-linkage, or those having non-polar side-chain groups without forming strong side-chain/backbone interactions.

Calculated bend probability of the Pro-Xaa portion of four oligopeptides Ac-Cys-Pro-Xaa-Cys-NHMe $(\mathrm{Xaa}=\mathrm{Val}, \mathrm{Phe}, \mathrm{Leu}$, and Nle) is summarized in Table VI with previous results for $\mathrm{Xaa}=\mathrm{Ala}$. It is clearly shown that the type III $\beta$-bend(including types I and VII) is an energetically favorable conformation for all four oligopeptides, and also that such tendency is more favorable for the Val and Phe residues having bulky side-chain groups than the Leu and Nle residues having relatively long side-chain groups. Such conformational character corresponds to the previous result that Ac-
Cys-Pro-Ala-Cys-NHMe has a tendency taking type III $\beta$-bend at the Pro-Ala portion. ${ }^{17}$ It means that the Pro-Xaa portion of Ac-Cys-Pro-Xaa-Cys-NHMe has common propensity forming the type III $\beta$-bend in the case that Xaa residue is a Ala-type residue having non-polar side-chain group. These results suggest that the Ala-residue approximation ${ }^{35}$ is also useful method for investigating basic conformational properties of oligopeptides and polypeptides as already shown in our previous works. ${ }^{9,36-39}$

For dipeptides such as Ac-Pro-Xaa-NHMe, calculated total bend-probability of the Pro-Xaa portion was $0.22,0.07,0.33$, and 0.26 for $\mathrm{Xaa}=\mathrm{Val}, \mathrm{Phe}, \mathrm{Leu}$, and Ala, respectively, ${ }^{21}$ and their bend types are not restricted to the type III. These results indicate the disulfide-linkage at Ac-Cys-Pro-Xaa-Cys-NHMe to be very important to stabilize the type III $\beta$-bend at Pro-Xaa portions. That is, it is suggested that the type III $\beta$-bend is constructed on the specific portion of the designed artificial protein by introducing the Cys-Pro-Xaa-Cys sequence into the amino-acid sequence using the Ala-type Xaa residue having non-polar side-chain group. Then, these results also suggest that disulfide-linkage is a very useful for constructing hairpin structures on protein backbones.

\section{REFERENCES}

1. M. Oka, Y. Baba, A. Kagemoto, and A. Nakajima, Polym. J., 21, 585 (1989).

2. K. Morita and M. Oka, Rept. Prog. Polym. Phys. Jpn., 35, 575 (1992).

3. M. Oka, S. Iwai, Y. Ishikawa, H. Hayashi, and M. Miyazawa, Peptide Chem., 1995, 457 (1996).

4. M. Oka, Y. Baba, A. Kagemoto, and A. Nakajima, Polym. J., 22, 135 (1990).

5. M. Oka, Y. Baba, A. Kagemoto, and A. Nakajima, Polym. J., 22, 555 (1990).

6. M. Oka and A. Nakajima, Peptide Chem., 1992, 275 (1993).

7. M. Oka, Rept. Prog. Polym. Phys. Jpn., 37, 591 (1994).

8. Y. Ishikawa, N. Takada, M. Oka, and A. Nishinaga, Peptide Chem., 1993, 461 (1994).

9. Y. Ishikawa, M. Oka, T. Hayashi, and A. Nishinaga, Polym. J., 28, 86 (1996).

10. M. Oka and T. Hayashi, Polym. J., 28, 95 (1996).

11. M. Oka and T. Hayashi, Peptide Chem., 1996, 449 (1997)

12. N. Nishi, I. Ohiso, N. Sakairi, S. Tokura, M. Tsunemi, and M. Oka, Biochem. Biophys. Res. Commun., 206, 981 (1995).

13. Y. Tanaka, K. Nagamoto, H. Sasaki, T. Fujimoto, N. Nishino, and M. Oka, Tetrahedron Lett., 37, 881 (1996).

14. T. Niidome, H. Mihara, T. Saiki, M. Oka, and H. Aoyagi, Peptide Chem., 1996, 185 (1997).

15. B. Kobe, Nature Struct. Biol., 3, 977 (1996).

16. J. Yoshimoto, A. Nishinaga, M. Oka, and T. Hayashi, Polym. Bull., 38, 109 (1997).

17. J. Yoshimoto, A. Nishinaga, M. Oka, and T. Hayashi, Polym. Bull., 38, 227 (1997).

18. J. Yoshimoto, A. Komatsu, A. Nishinaga, M. Oka, and T. Hayashi, Polym. Bull., 39, 377 (1997).

19. F. A. Momany, R. F. McGuire, A. W. Burgess, and H. A. Scheraga, J. Phys. Chem., 79, 361 (1975).

20. M. J. D. Powell, Computer J., 7, 155 (1964).

21. S. S. Zimmerman and H. A. Scheraga, Biopolymers, 16, 811 (1977).

22. V. F. Bystrov, Prog. NMR Spectroscopy, 10, 41 (1976).

23. S. S. Zimmerman, M. S. Pottle, G. Nemethy, and H. A. Scheraga, Macromolecules, 10, 1 (1977).

24. M. Sisido, private communications.

25. Y. Beppu, Computer and Technology, 13, 101 (1989).

26. C. M. Falcomer, Y. C. Meinwald, I. Choudhary, S. Talluri, P. J. Milburn, J. Clardy, and H. A. Scheraga, J. Am. Chem. Soc., 
114, 4036 (1992).

27. Y. V. Venkatachalapathi, B. V. V. Prasad, and P. Balaram, Biochemistry, 21, 5502 (1982).

28. R. Kishore, S. Raghothama, and P. Balaram, Biochemistry, 27, 2462 (1988).

29. R. Kishore, H. Ishizaki, A. T. Tu, A. Ravi, and P. Balaram, Int. J. Peptide Protein Res., 30, 474 (1987)

30. B. N. N. Rao, A. Kumar, H. Balaram, A. Ravi, and P. Balaram, J. Am. Chem. Soc., 105, 7423 (1983).

31. A. Ravi and P. Balaram, Tetrahedron, 40, 2577 (1984).

32. M. Oka, Y. Baba, A. Kagemoto, and A. Nakajima, Polym. Bull., 25, 701 (1991)

33. M. A. Khaled, V. Renugopalakrishnan, and D. W. Urry, J. Am.
Chem. Soc., 98, 7547 (1976).

34. V. Renugopalakrishnan, M. A. Khaled, R. S. Papaka, and D. W. Urry, Biomolecular Structure Conformation, Function and Evolution, 2, 545 (1980).

35. M. Oka and T. Hayashi, Rept. Prog. Polym. Phys. Jpn., 39, 553 (1996).

36. M. Oka and A. Nakajima, Polym. J., 16, 693 (1984).

37. M. Oka, T. Hayashi, and A. Nakajima, Polym. J., 17, 621 (1985).

38. M. Oka, Y. Baba, A. Kagemoto, and A. Nakajima, Polym. Bull., 21, 377 (1989)

39. M. Oka, Y. Baba, A. Kagemoto, and A. Nakajima, Polym. Bull., 21, 385 (1989) 